\title{
Flow Injection Determination of Tramadol Based on Its Sensitizing Effect on the Chemiluminescent Reaction of Permanganate-Sulfite
}

\author{
Xun Yao, Jingkai Zhang, Jianguo $\mathrm{Li}^{*}$ \\ College of Chemistry, Chemical Engineering and Materials Science, Soochow University, Suzhou, China \\ E-mail: ${ }^{2}$ lijgsd@suda.edu.cn \\ Received July 14, 2011; revised August 15, 2011; accepted August 27, 2011
}

\begin{abstract}
In this paper, a novel chemiluminescence (CL) method for the determination of tramadol has been developed by combining the flow injection technique and its sensitizing effect on the weak CL reaction between sulfite and acidic $\mathrm{KMnO}_{4}$. A mechanism for the CL reaction has been proposed on the basis of fluorescent and CL spectra. Under the optimized conditions, the proposed method allows the measurement of tramadol hydrochloride over the range of $0.04-4 \mu \mathrm{g} / \mathrm{mLwith}$ a correlation coefficient of $0.9995(n=8)$ and a detection limit of $0.01 \mu \mathrm{g} / \mathrm{mL}(3 \sigma)$, and the relative standard deviation for $2.0 \mu \mathrm{g} / \mathrm{mL}$ tramadol $(n=11)$ is $2.1 \%$. The utility of this method was demonstrated by determining tramadol hydrochloride in tablets and injections.
\end{abstract}

Keywords: Chemiluminescence, Tramadol hydrochloride, $\mathrm{KMnO}_{4}$, Sodium Sulfite, Flow-Injection Analysis

\section{Introduction}

Tramadol $[( \pm)$ trans-2-(dimethylaminomethyl)-1-(3-methoy-phenyl)-cyclohexanol] (Figure 1) hydrochloride is a centrally acting analgesic agent which possesses an analgetic action with a potency ranging between weak opioids and morphine $[1,2]$. It is mainly metabolized by liver and essentially excreted by the kidney [2,3]. Clinical studies have shown that respiratory depression, pronounced opioid side-effect profile and analgetic tolerance hardly happen after repeated administration are observed with tramadol [4]. Therefore, it is successfully used since 1977 for the relief of short-term and long-term pains which may be induced by the different illnesses or traumas in the world [5].

Various methods have been reported for the determination of tramadol hydrochloride in biological fluids and in pharmaceutical preparations, including HPLC [6-11], HPTLC [12], GC [13,14], capillary electrophoresis(CE) $[15,16]$, spectrophotometry [17-19], voltammetry [20] and potentiometry [21]. Each of the above methods had its own merits and disadvantages, for example, some of them were accurate and selective, but involved expensive instrumentation and were time consuming, needed preconcentration before determination because of lacking high sensitive detector; some were inherent simple but have low sensitivity . Therefore, it is very important to develop a rapid, simple, sensitive and accurate method for the determination of tramadol in order to obtain optimal therapeutic concentrations for quality assurance in pharmaceutical preparations.

Flow-injection chemilluminescence(CL) methods are powerful analytical techniques that have been frequently used for the analysis of pharmaceuticals in recent years and have excellent sensitivity, wide linear dynamic range, a high degree of reproducibility, which requires relatively simple and inexpensive instrumentation [22-25]. To the best of our knowledge, up to the present time, nothing has been published concerning the determination of tramadol with a flow injection CL method.

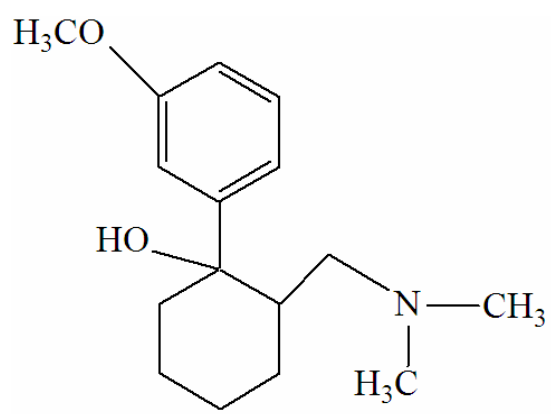

Figure 1. Chemical structures of tramadol. 
In order to develop a simple, rapid, and sensitive method for the determination of tramadol hydrochloride in both pure form and its pharmaceutical preparations, this work studied the sensitizing effect of tramadol on the CL intensity emitted from the reaction of sulfite with acidic $\mathrm{KMnO}_{4}$. A method for tramadol detection is proposed on the basis of this sensitizing effect. This method is simple and less expensive than the above-mentioned techniques and at the same time offers good accuracy and precision. Combining with flow injection technique, this effect provides a sensitive and convenient method for the determination of tramadol in pharmaceutical preparations. It has been used to determine tramadol hydrochloride in tablets and injections successfully. The possible CL reaction mechanism has also been discussed on the basis of CL spectra.

\section{Experimental}

\subsection{Apparatus}

The CL emission was recorded with a set of flow-injection CL analyzer (IFFL-E, Xi'an Ruike Electronic equipment Corporate, Xi'an, China). The schematic diagram of the flow-injection CL analytical system was shown in Figure 2. Two peristaltic pumps were used to deliver flow streams. PTFE tubing $(0.8 \mathrm{~mm}$ i.d. $)$ was used to connect all components in the flow system. A flow cell that positioned in front of the detection window of the photomultiplier tube (PMT) (CR-105, Hamamatsu, Beijing, China) was a $25 \mathrm{~cm}$ length of spiral glass tubing (1.0 $\mathrm{mm}$ i.d.) and the distance between injection valve and flow cell was about $10 \mathrm{~cm}$. Sample solution of tramadol hydrochloride was injected into $\mathrm{Na}_{2} \mathrm{SO}_{3}$ carrier stream using a six-way injection valve equipped with a $80 \mu \mathrm{L}$ sample loop, merged with $\mathrm{KMnO}_{4}$ solution stream, and then generated CL emission in the flow cell. The CL signal was detected by the PMT with no wavelength discrimination and recorded with computer employing an IFFL-E flow-injection CL analysis system software. The fluorescence and absorption spectra were monitored using a F-2500 fluorescence spectrometer (Hitachi, Tokyo, Japan) and a Shimadzu UV-2450 UV-visible recording spectrophotometer (Shimadzu, Kyoto, Japan), respectively. The CL spectrum was obtained with a series interference filters by the static method. The filters were inserted between the sample cuvette and the photomultiplier tube (PMT).

\subsection{Reagents and Chemicals}

Pure powders of tramadol hydrochloride was obtained from Nanjing Institute for Drug Control (Nanjing, China). $\mathrm{KMnO}_{4}$ and $\mathrm{Na}_{2} \mathrm{SO}_{3}$ were purchased from Shanghai Chemical Reagent Limited Company (Shanghai, China). All other reagents and chemicals were commercially available and of analytical reagent grade. All solutions were prepared with sub-boiling distilled deionized water.

The standard solution of tramadol hydrochloride $(1.000 \mathrm{mg} / \mathrm{ml})$ was prepared by dissolving $0.0500 \mathrm{~g}$ tramadol hydrochloride with water and diluting to $50 \mathrm{~mL}$ with water, stored in the refrigerator $\left(4^{\circ} \mathrm{C}\right)$ and diluted as required daily. The $\mathrm{Na}_{2} \mathrm{SO}_{3}$ solution $\left(1.0 \times 10^{-2} \mathrm{~mol} / \mathrm{L}\right)$ was prepared by dissolving $0.1260 \mathrm{~g} \mathrm{Na}_{2} \mathrm{SO}_{3}$ with $100 \mathrm{~mL}$ water daily and kept in a dark place. Potassium permanganate solution $\left(1.0 \times 10^{-2} \mathrm{~mol} / \mathrm{L}\right)$ was prepared by dissolving $1.58 \mathrm{~g}$ of $\mathrm{KMnO}_{4}$ in $1 \mathrm{~L}$ of boiled water and filtering through glass wool.

\subsection{Procedure}

As shown in Figure 2, flow lines (a-d) were connected with tramadol hydrochloride solution, $\mathrm{Na}_{2} \mathrm{SO}_{3}$ solution, water and $\mathrm{KMnO}_{4}$ with $\mathrm{H}_{2} \mathrm{SO}_{4}$ solution, respectively. Flow rate was set at $4.2 \mathrm{~mL} / \mathrm{min}$ for the $\mathrm{KMnO}_{4}$ solution and water, respectively; sample and $\mathrm{Na}_{2} \mathrm{SO}_{3}$ solution at $2.5 \mathrm{~mL} / \mathrm{min}$. Pumps were started to wash the whole system until a stable blank signal was recorded. A $80 \mu \mathrm{L}$ mixture of tramadol and $\mathrm{Na}_{2} \mathrm{SO}_{3}$ was injected into the carrier stream $\left(\mathrm{H}_{2} \mathrm{O}\right)$, which was merged with acidic $\mathrm{KMnO}_{4}$ solution for producing CL signal. The concentration of tramadol hydrochloride was quantified by the CL intensity (peak height).

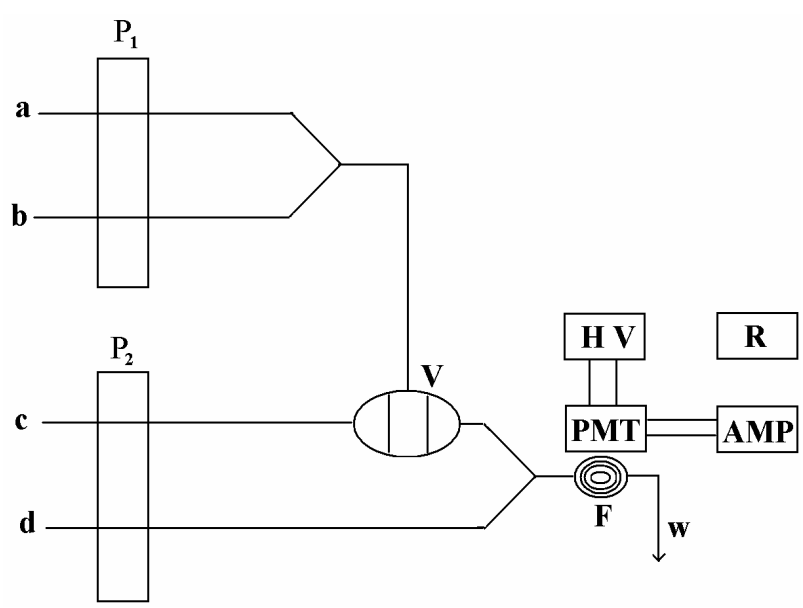

Figure 2. Schematic diagram of CL flow system. a, tramadol; b, sodium sulfite solution; c, carrier $\left(\mathrm{H}_{2} \mathrm{O}\right) ; \mathrm{d}, \mathrm{KMnO}_{4} ; \mathrm{P}_{1}$ and $P_{2}$, peristaltic pump; $V$, six-way injection valve; $F, C L$ flow cell; PMT, photomultiplier tube; HV, negative high voltage supply; AMP, amplitude; $R$, recorder; $W$, waste solution. 


\section{Results and Discussion}

\subsection{The Kinetic Characteristics of the $C L$ Reaction}

The kinetic characteristics of the CL reaction were studied by a stop-flow injection method after the baseline was steadily recorded. Then $3.0 \times 10^{-3} \mathrm{~mol} / \mathrm{L} \mathrm{Na}_{2} \mathrm{SO}_{3}$ was injected into $0.08 \mathrm{~mol} / \mathrm{L}$ sulphuric acid solution containing $1.0 \times 10^{-4} \mathrm{~mol} / \mathrm{L} \mathrm{KMnO}_{4}$ and the $\mathrm{CL}$ kinetic curve was simultaneously recorded by IFFM-E luminometer (see Figure 3, dashed line). Solid line in Figure 3 was the CL kinetic curve obtained when the mixture solution of $2.0 \mu \mathrm{g} / \mathrm{mL}$ tramadol and $3.0 \times 10^{-3} \mathrm{~mol} / \mathrm{L}$ $\mathrm{Na}_{2} \mathrm{SO}_{3}$ were injected into $0.6 \mathrm{~mol} / \mathrm{L}$ sulphuric acid solution containing $1.0 \times 10^{-4} \mathrm{~mol} / \mathrm{L} \mathrm{KMnO}_{4}$. It was found that the rate of the reaction was so fast that the CL intensity reached the peak maximum only $0.7 \mathrm{~s}$ from reagent mixing, and it took about $0.8 \mathrm{~s}$ for the signal decline to the base line. The results indicate that the CL signal was remarkably increased in the presence of tramadol.

\subsection{Optimization of the Experimental Conditions}

To establish the optimum conditions for the determination of tramadol hydrochloride, various parameters were investigated using a series of univariate approachs which were performed on reagent concentration, conditions of reaction medium, reagent flow rate and injection sample volume.

The kinds and concentration of acids in the reaction system influence the $\mathrm{CL}$ intensity. Therefore, six different acids including $\mathrm{HCl}, \mathrm{HNO}_{3}, \mathrm{CH}_{3} \mathrm{COOH}, \mathrm{H}_{3} \mathrm{PO}_{4}$, $\mathrm{H}_{6} \mathrm{P}_{4} \mathrm{O}_{13}$ or $\mathrm{H}_{2} \mathrm{SO}_{4}$ of different concentration in the range of $0.02-0.2 \mathrm{~mol} / \mathrm{L}$ were tested, respectively. The results showed the best signal was obtained in sulphuric acid, so sulphuric acid was selected as the optimum medium. With the increasing concentration of $\mathrm{H}_{2} \mathrm{SO}_{4}$, the $\mathrm{CL}$ intensity increased and reached a maximum value at 0.08 $\mathrm{mol} / \mathrm{L}$ (Figure 4). Thus, $0.08 \mathrm{~mol} / \mathrm{L} \mathrm{H}_{2} \mathrm{SO}_{4}$ was selected as the acidic medium for the $\mathrm{KMnO}_{4}$ solution.

The effect of $\mathrm{KMnO}_{4}$ concentration on CL intensity was examined in the range of $0.2 \times 10^{-4}$ to $1.6 \times 10^{-4}$ $\mathrm{mol} / \mathrm{L}$ (Figure 5). With the increasing concentration of $\mathrm{KMnO}_{4}$, the CL intensity increased and reached a flat value at $1.0 \times 10^{-4} \mathrm{~mol} / \mathrm{L}$. Thus, $1.0 \times 10^{-4} \mathrm{~mol} / \mathrm{L} \mathrm{KMnO}_{4}$ concentration was chosen for further experiments.

The effect of $\mathrm{Na}_{2} \mathrm{SO}_{3}$ concentration upon the $\mathrm{CL}$ intensity was examined within the range of $1.0 \times 10^{-3}$ to $4.0 \times 10^{-3} \mathrm{~mol} / \mathrm{L}$ (Figure 6). With the increase of $\mathrm{Na}_{2} \mathrm{SO}_{3}$ concentration, the $\mathrm{CL}$ intensity increased and reached a maximum value at $3.0 \times 10^{-3} \mathrm{~mol} / \mathrm{L}$. Therefore,
$3.0 \times 10^{-3} \mathrm{~mol} / \mathrm{L}$ was used as the optimum concentration of $\mathrm{Na}_{2} \mathrm{SO}_{3}$.

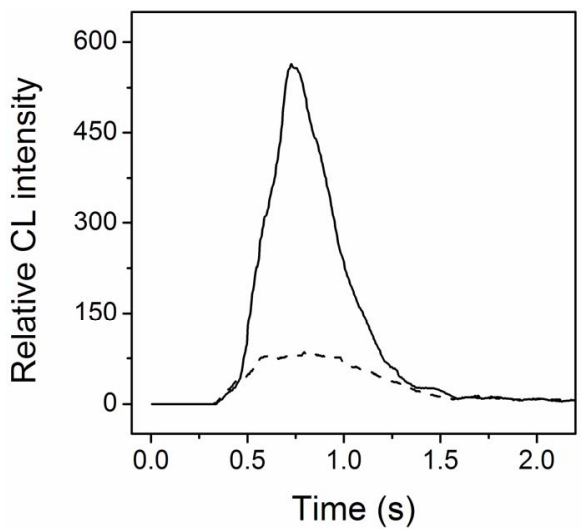

Figure 3. CL intensity-time profiles of $\mathrm{KMnO}_{4}-\mathrm{Na}_{2} \mathrm{SO}_{3}$ reaction (dashed line) and $\mathrm{KMnO}_{4}-\mathrm{Na}_{2} \mathrm{SO}_{3}$-tramadol hydrochloride reaction(solid line).

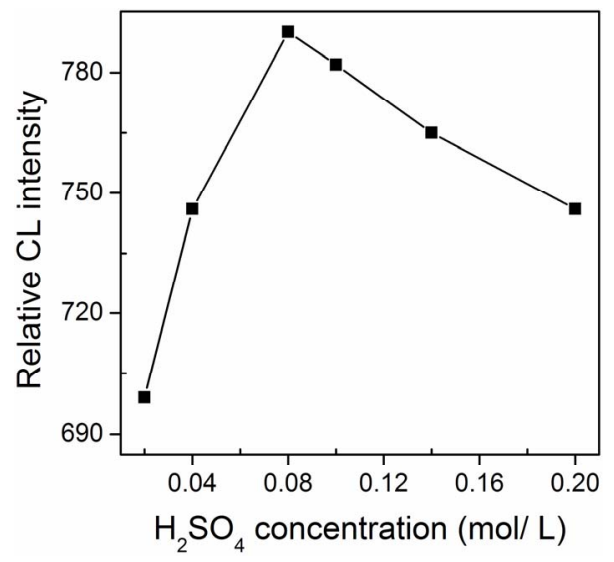

Figure 4. Effect of $\mathrm{H}_{2} \mathrm{SO}_{4}$ concentration on $\mathrm{CL}$ intensity of $1.0 \times 10^{-4} \mathrm{~mol} / \mathrm{L} \mathrm{KMnO}_{4}+1.0 \mu \mathrm{g} / \mathrm{mL}$ tramadol hydrochloride $+3.0 \times 10^{-3} \mathrm{~mol} / \mathrm{L} \mathrm{Na}_{2} \mathrm{SO}_{3}$.

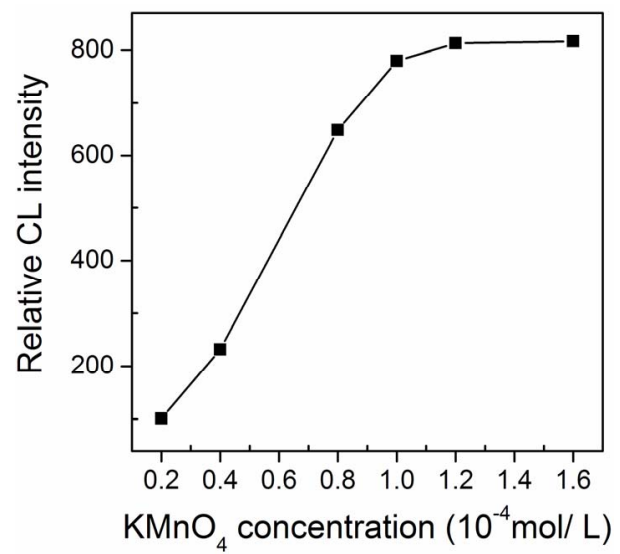

Figure 5. Effect of $\mathrm{KMnO}_{4}$ concentration in $0.08 \mathrm{~mol} / \mathrm{L}$ $\mathrm{H}_{2} \mathrm{SO}_{4}$ on $\mathrm{CL}$ intensity of $1.0 \mu \mathrm{g} / \mathrm{mL}$ tramadol hydrochloride $+3.0 \times 10^{-3} \mathrm{~mol} / \mathrm{L} \mathrm{Na}_{2} \mathrm{SO}_{3}$. 


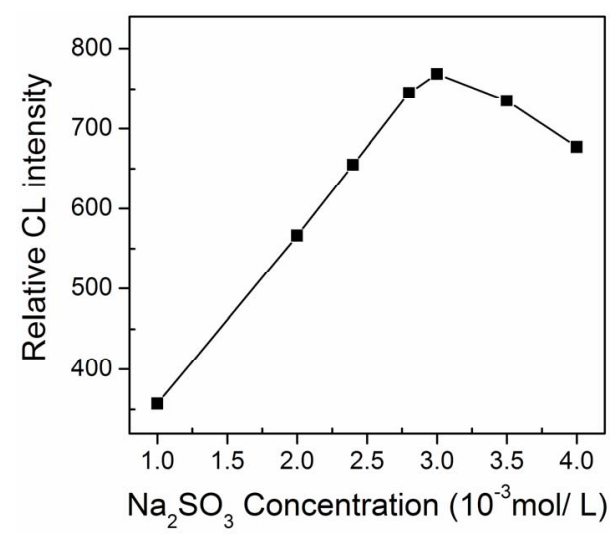

Figure 6. Effect of $\mathrm{Na}_{2} \mathrm{SO}_{3}$ concentration on CL intensity of $1.0 \mu \mathrm{g} / \mathrm{mL}$ tramadol hydrochloride $+1.0 \times 10^{-4} \mathrm{~mol} / \mathrm{L}$ $\mathrm{KMnO}_{4}$ concentration in $0.08 \mathrm{~mol} / \mathrm{L} \mathrm{H}_{2} \mathrm{SO}_{4}$.

Because the proposed CL reaction was very fast, the distance between Y-shaped mixing element and the flow cell was made to be as short as possible, and the flow rate of pump $\mathrm{P}_{2}$ was studied in the range of 1.0 to 6.0 $\mathrm{mL} / \mathrm{min}$ in order to determine the maximum of the $\mathrm{CL}$ signal. When the flow rate was $4.2 \mathrm{~mL} / \mathrm{min}$, the relative CL intensity, reproducibility of signal, peak shape, and ratio of signal to noise was the best. Therefore, the flow rate of $4.2 \mathrm{~mL} / \mathrm{min}$ was employed throughout the experiment.

At the flow rate of $4.2 \mathrm{~mL} / \mathrm{min}$, the determination of tramadol hydrochloride, including sampling and washing, could be performed in 20 s, giving a sample measurement frequency of about 180 samples per hour. Thus, it was decided to supply the $\mathrm{KMnO}_{4}$ solution and carrier stream at $4.2 \mathrm{~mL} / \mathrm{min}$, respectively. Considering the reagent consumption, $2.5 \mathrm{~mL} / \mathrm{min}$ was chosen as the flow rate of the sample and $\mathrm{Na}_{2} \mathrm{SO}_{3}$ solution.

In flow injection analysis, it is necessary to optimize the injection volume to achieve the desired sensitivity. The influence of the sample injection volume on the $\mathrm{CL}$ intensity was tested at $40,60,80,100$ and $120 \mu \mathrm{L}$ of 2.0 $\mu \mathrm{g} / \mathrm{mL}$ tramadol hydrochloride. The biggest relative $\mathrm{CL}$ intensity and the best ratio of signal to noise were obtained when it was fixed between 80 and $100 \mu \mathrm{L}$. Thus, a $80 \mu \mathrm{L}$ sample solution was injected into the carrier stream.

\subsection{Analytical Characteristics of Tramadol Hydrochloride}

Under the optimum conditions mentioned above, the relative CL intensity was linearly related to the concentration of tramadol hydrochloride from 0.04 to $4 \mu \mathrm{g} / \mathrm{mL}$. Figure 7 shows the flow injection chemiluminescence signals for tramadol. The maximum peak height increased linearly with the increasing of tramadol concentration, with a linear regression equation of $\Delta I$ (relative units) $=$ $754.1 c(\mu \mathrm{g} / \mathrm{mL})+121.6(\mathrm{r}=0.9995, n=8)$. The detection limit was $0.01 \mu \mathrm{g} / \mathrm{ml}$, which was calculated according to IUPAC regulation that is three times of standard deviation of blank value $(3 \sigma)$. The relative standard deviation for 11 parallel determinations of $1.0 \mu \mathrm{g} / \mathrm{mL}$ tramadol was $2.1 \%$, showing a good reproducibility.

\subsection{Interferences Experiments}

The influence of some common inorganic ion and related organic compounds was studied by the determination of $1.0 \mu \mathrm{g} / \mathrm{ml}$ tramadol hydrochloride solution. The tolerance limit was taken as the amount which caused a relative error $\pm 5 \%$ in the peak height. The results were shown in Table 1 that some ions and the studied excipients in the tablets did not interfere with the determination of tramadol hydrochloride in this system. Therefor, this method can be used for the determination of tramadol hydrochloride in pharmaceutical preparations.

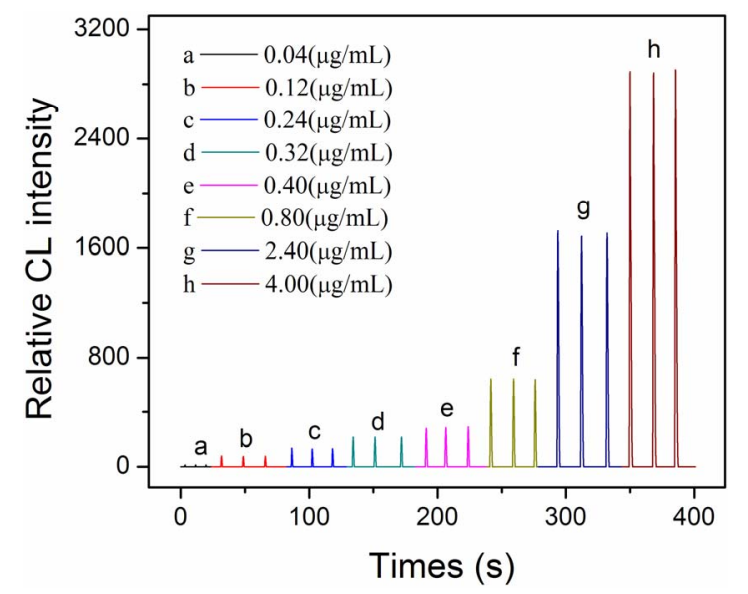

Figure 7. Typical recorder response for the determination of tramadol (a-h).

Table1. Tolerance to different substances in the determination of $1.0 \mu \mathrm{g} / \mathrm{mL}$ tramadol hydrochloride.

\begin{tabular}{cc}
\hline Species added & Maximum tolerable ratio \\
\hline $\mathrm{Na}^{+}, \mathrm{K}^{+}, \mathrm{Mg}^{2+}, \mathrm{Zn}^{2+}, \mathrm{Al}^{3+}, \mathrm{NO}_{3}^{-}$ & 500 \\
$\mathrm{Ca}^{2+}, \mathrm{Cu}^{2+}$ & 100 \\
starch, $\mathrm{Fe}^{3+}, \mathrm{Pb}^{2+}$ & 50 \\
glucose, sucrose, $\mathrm{CH}_{3} \mathrm{COO}^{-}$ & 20 \\
Citric acid, $\mathrm{Ni}^{2+}, \mathrm{Cr}^{3+}$ & 10 \\
ascorbic acid, tartaric acid & 5 \\
\hline
\end{tabular}




\subsection{Determination of Tramadol Hydrochloride in Pharmaceutical Preparations}

The proposed method was successfully applied to the determination of tramadol in a commercial pharmaceutical formulation. The tramadol hydrochloride tablets and injections from different manufacturers were bought from the local market. The average content of tablets was calculated from the contents of 25 tablets, they were then finely ground, homogenized and a portion of the powder which was equivalent to $20 \mathrm{mg}$ was weighed accurately and diluted with $50 \mathrm{~mL}$ water. The mixture was sonicated for $10 \mathrm{~min}$ and then filtrated. The filtrate was diluted further with water. On the contrary, the injection of tramadol hydrochloride needed not any pre-treatment. The sample solution was prepared by directly diluting the injection and the filtrate with water in order that the concentration of tramadol was in the working range of its determination. According to the proposed method, tramadol hydrochloride was determined and the results were shown in Table 2. The $t$-test indicated that there were no significant differences between the results obtained by the proposed method and those obtained by the Chinese Pharmacopoeia method at confidence level of $95 \%$.

\subsection{Possible CL Mechanism}

The reaction of sulphite with strong oxidants such as $\mathrm{KMnO}_{4}$ in acid media is accompanied by a weak CL that has been reported extensively $[26,27]$, it is proposed that the excited $\mathrm{SO}_{2}^{*}$ is the emitter and the emission spectrum is between 450 and $600 \mathrm{~nm}[28,29]$. This weak CL reaction can be sensitized by not only several fluorescent, which is the energy-transfer mechanism[22,30] but also non-fluorescent compounds such as 3-cyclohexylaminopropane sulfonic acid (CAPS) [31], ibuprofen[32] and iproniazid [33] etc. Although the causes of the sensitiz- ing action of these non-fluorescent compounds are different from each other, the sensitizing effect of CAPS is attribute to the presence of the cyclohexyl ring $[31,34]$.

On the one hand the molecule of tramadol hydrochloride (Figure 1) contains a cyclohexyl ring, on the other hand the CL spectrum of $\mathrm{KMnO}_{4}-\mathrm{Na}_{2} \mathrm{SO}_{3}-\mathrm{H}_{2} \mathrm{SO}_{4}$ system in the presence and absence of tramadol hydrochloride showed similar emission profile extending from 450 to $600 \mathrm{~nm}$ (Figure 8), which was measured by means of a series of interference filters. According to the suggested reports, the emitter is the excited sulfur dioxide. Therefore, it may be concluded that tramadol hydrochloride played a role of an enhancer in the reaction.

The fluorescence spectra of tramadol solution were scanned in the range $250-700 \mathrm{~nm}$, using a F-2500 fluorescence spectrometer (Hitachi, Tokyo, Japan). Since the fluorescence spectrum of tramadol $\left(\lambda_{\mathrm{ex}}=200 \mathrm{~nm}, \lambda_{\mathrm{em}}=\right.$ $300 \mathrm{~nm}$ ) was not identical with the CL spectrum obtained, and the reaction product of $\mathrm{KMnO}_{4}$ with tramadol was a non-fluorescent compound, an energy-transfer mechanism was excluded.

The absorbance spectra of $\mathrm{KMnO}_{4}-\mathrm{H}_{2} \mathrm{SO}_{4}$ solution and $\mathrm{KMnO}_{4}-\mathrm{H}_{2} \mathrm{SO}_{4}$-tramadol solution were scanned (Figure 9). The absorbance peaks of $\mathrm{KMnO}_{4}$ at $524 \mathrm{~nm}$ and 545 $\mathrm{nm}$ decreased in the presence of tramadol and the decreased quantity was related to the concentration of tramadol. According to the suggestion reported in [32], the mechanism of tramadol- $\mathrm{KMnO}_{4}-\mathrm{Na}_{2} \mathrm{SO}_{3}-\mathrm{H}_{2} \mathrm{SO}_{4}$ system could be expressed as follows:

$$
\begin{aligned}
& \mathrm{MnO}_{4}^{-}+\mathrm{HSO}_{3}^{-} \rightarrow \mathrm{HSO}_{3}^{*}+\mathrm{MnO}_{4}^{2-} \\
& 2 \mathrm{HSO}_{3}^{-} \rightarrow \mathrm{S}_{2} \mathrm{O}_{6}^{2-}+2 \mathrm{H}^{+} \\
& \mathrm{S}_{2} \mathrm{O}_{6}^{2-} \rightarrow \mathrm{SO}_{4}^{2-}+\mathrm{SO}_{2}^{*} \\
& \mathrm{KMnO}_{4}+\text { tramadol } \rightarrow \text { products }+ \text { energy } \\
& \mathrm{SO}_{2}+\text { energy } \rightarrow \mathrm{SO}_{2}^{*} \\
& \mathrm{SO}_{2}^{*} \rightarrow \mathrm{SO}_{2}+\mathrm{h} v
\end{aligned}
$$

\begin{tabular}{|c|c|c|c|c|c|}
\hline Samples & $\begin{array}{l}\text { Nominal } \\
\text { Content }\end{array}$ & $\begin{array}{l}\text { Proposed } \\
\text { Method }\end{array}$ & $\begin{array}{c}\text { RSD } \\
(\%, n=5)\end{array}$ & $\begin{array}{c}\text { Pharmacopoeia } \\
\text { Method }\end{array}$ & $\begin{array}{c}\text { RSD } \\
(\%, n=5)\end{array}$ \\
\hline Injection $1(\mathrm{H} 20023786)$ & $50 \mathrm{mg} / 2 \mathrm{~mL}$ & $\begin{array}{l}49.7 \pm 0.4 \\
(\mathrm{mg} / 2 \mathrm{~mL})\end{array}$ & 2.0 & $49.8 \pm 0.2$ & 1.6 \\
\hline $\begin{array}{c}\text { Injection } 2 \\
(\mathrm{~J} 20020086)\end{array}$ & $100 \mathrm{mg} / 2 \mathrm{~mL}$ & $\begin{array}{l}99.9 \pm 0.5 \\
(\mathrm{mg} / 2 \mathrm{~mL})\end{array}$ & 1.8 & $99.7 \pm 0.4$ & 1.5 \\
\hline $\begin{array}{c}\text { Tablet } 1 \\
(\mathrm{H} 20033330)\end{array}$ & $100 \mathrm{mg} /$ tablet & $\begin{array}{l}99.7 \pm 0.6 \\
(\mathrm{mg} / 2 \mathrm{~mL})\end{array}$ & 1.9 & $99.6 \pm 0.3$ & 1.4 \\
\hline Tablet 2 (H10960043) & $50 \mathrm{mg} /$ tablet & $\begin{array}{l}49.6 \pm 0.7 \\
(\mathrm{mg} / 2 \mathrm{~mL})\end{array}$ & 2.1 & $49.7 \pm 0.5$ & 1.5 \\
\hline
\end{tabular}

Table 2. Results of determinationof tramadol hydrochloride in injections and tablets. 


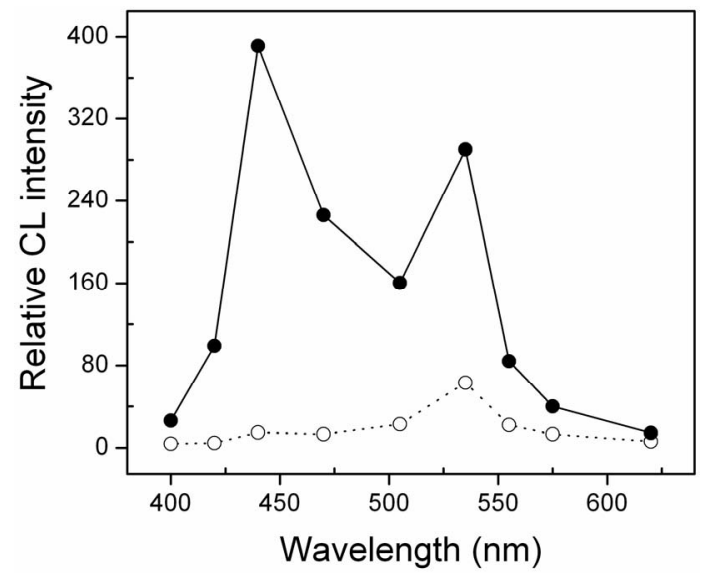

Figure 8. CL spectra of $1.0 \times 10^{-4} \mathrm{~mol}^{-} \mathrm{LKMnO}_{4}+3.0 \times 10^{-3}$ $\mathrm{mol} / \mathrm{LNa}_{2} \mathrm{SO}_{3}$ (dashed line) and $20.0 \mu \mathrm{g} / \mathrm{mL}$ tramadol hydrochloride $+1.0 \times 10^{-4} \mathrm{~mol} / \mathrm{LKMnO}_{4}+3.0 \times 10^{-3} \mathrm{~mol} / \mathrm{L}$ $\mathrm{Na}_{2} \mathrm{SO}_{3}$ (solid line).

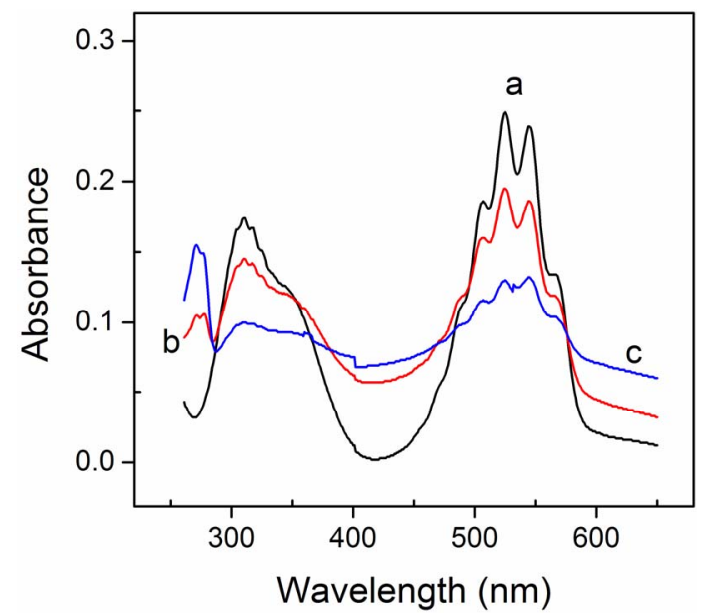

Figure 9. Absorbance spectra of: (a) $1.0 \times 10^{-4} \mathrm{~mol} / \mathrm{L}$ $\mathrm{KMnO}_{4}+0.08 \mathrm{~mol} / \mathrm{L} \mathrm{H}_{2} \mathrm{SO}_{4}$; (b) $1.0 \times 10^{-4} \mathrm{~mol} / \mathrm{L} \mathrm{KMnO}_{4}+$ $0.08 \mathrm{~mol} / \mathrm{L} \mathrm{H}_{2} \mathrm{SO}_{4}+10.0 \mu \mathrm{g} / \mathrm{mL}$ tramadol; and (c) $1.0 \times 10^{-4}$ $\mathrm{mol} / \mathrm{L} \mathrm{KMnO} \mathrm{KM}_{4}+0.08 \mathrm{~mol} / \mathrm{L} \mathrm{H}_{2} \mathrm{SO}_{4}+20.0 \mu \mathrm{g} / \mathrm{mL}$ tramadol.

The CL of $\mathrm{KMnO}_{4}-\mathrm{Na}_{2} \mathrm{SO}_{3}$ reaction was very weak. The CL signal was remarkably increased in the presence of tramadol. Therefore, it can be concluded that tramadol played a role of an enhancer in the reaction.

\section{Conclusions}

A new flow injection CL method was proposed for the determination of tramadol hydrochloride based on the $\mathrm{KMnO}_{4}$-sodium sulfite system. The experimental conditions affecting the CL reaction were optimized and the analytical characteristics for the determination of tramadol hydrochloride are presented here. The possible CL reaction mechanism has also been discussed. The proposed method has a simple, rapid, inexpensive and high sensi- tivity for the determination of tramadol hydrochloride in tablets. This method is practical and valuable in clinical and biochemical laboratories for the determination of tramadol.

\section{Acknowledgements}

This work was supported by the Science Fund from the National Natural Science Foundation of China (No. 21075087), the Provision Science Fund from Soochow University (No. Q3109955), the Open Project Program of State Key Laboratory of Food Science and Technology, Jiangnan University (No. SKLF-KF-200908), Education bureau of Jiangsu Province (No. 08KJB150014).

\section{References}

[1] P. Dayer, J. Desmeules and L. Collart, "Pharmacology of Tramadol,” Drugs, Vol. 53, No. 2, 1997, pp. 18-24. doi:10.2165/00003495-199700532-00006

[2] P. Dayer, L. Collart and J. Desmeules, "The Pharmacology of Tramadol," Drugs, Vol. 47, No. 1, 1994, pp. 3-7. doi:10.2165/00003495-199400471-00003

[3] C. R. Lee, D. Mctavish and E. M. Sorkin, "Tramadol. A Preliminary Review of Its Pharmacodynamic and Pharmacokinetic Properties, and Therapeutic Potential in Acute and Chronic Pain States," Drugs, Vol. 46, No. 2, 1993, pp. 313-340. doi:10.2165/00003495-199346020-00008

[4] L. Poulsen, L. Arendt-Nielsen, K. Brosen and S. H. Sindrup, "The Hypoalgesic Effect of Tramadol in Relation to CYP2D6," Clinical Pharmacology \& Therapeutics, Vol. 60, No. 6, 1996, pp. 636-644.

doi:10.1016/S0009-9236(96)90211-8

[5] W. Lintz, H. Barth, G. Osterloh and E. Schmidt-Böthelt, "Pharmacokinetics of Tramadol and Bioavailability of Enteral Tramadol Formulations. 3rd Communication: Suppositories," Drug Research, Vol. 48, No. 9, 1998, pp. 889- 899.

[6] Y. H. Ardakani, R. Mehvar, A. Foroumadi and M. R. Rouini, "Enantioselective Determination of Tramadol and Its Main Phase I Metabolites in Human Plasma by High-Performance Liquid Chromatography," Journal of Chromatography B, Vol. 864, No. 1-2, 2008, pp. 109-115. doi:10.1016/j.jchromb.2008.01.038

[7] H. Ebrahimzadeh, Y. Yamini, A. Sedighi and M. R. Rouini, "Determination of Tramadol in Human Plasma and Urine Samples Using Liquid Phase Microextraction with Back Extraction Combined with High Performance Liquid Chromatography," Journal of Chromatography B, Vol. 863, No. 2, 2008, pp. 229-234. doi:10.1016/j.jchromb.2008.01.005

[8] Y. H. Ardakani and M. R. Rouini, "Improved Liquid Chromatographic Method for the Simultaneous Determination of Tramadol and Its Three Main Metabolites in Human Plasma, Urine and Saliva," Journal of Pharma- 
ceutical and Biomedical Analysis, Vol. 44, No. 5, 2007, pp. 1168-1173. doi:10.1016/j.jpba.2007.04.012

[9] M. Zečević, Ž. Stanković, L. Živanović and B. Jocić, "Validation of a High-Performance Liquid ChromaTographic Method for the Simultaneous Determination of Tramadol and Its Impurities in Oral Drops as a Pharmaceutical Formulation," Journal of Chromatography A, Vol. 1119, No. 1-2, 2006, pp. 251-256. doi:10.1016/i.chroma.2005.11.105

[10] M. R. Rouini, Y. H. Ardakani, F. Soltani , H. Y. AboulEnein and A. Foroumadi, "Development and Validation of a Rapid HPLC Method for Simultaneous Determination of Tramadol, and Its Two Main Metabolites in Human Plasma," Journal of Chromatography B, Vol. 830, No. 2, 2006, pp. 207-211. doi:10.1016/j.jchromb.2005.10.039

[11] L. Vlase, S. E. Leucuta and S. Imre, "Determination of Tramadol and O-Desmethyltramadol in Human Plasma by High-Performance Liquid Chromatography with Mass Spectrometry Detection," Talanta, Vol. 75, No. 4, 2008, pp. 1104-1109. doi:10.1016/j.talanta.2008.01.006

[12] J. Krzek and M. Starek, "Quality Assessment for Tramadol in Pharmaceutical Preparations with Thin Layer Chromatography and Densitometry," Biomedical Chromatography, Vol. 18, No. 8, 2004, pp. 589-599. doi:10.1002/bmc.361

[13] C. Moore, S. Rana and C. Coulter, "Determination of Meperidine, Tramadol and Oxycodone in Human Oral Fluid Using Solid Phase Extraction and Gas Chromatogramphy-Mass Spectrometry," Journal of Chromatography $B$, Vol. 850, No. 1-2, 2007, pp. 370-375. doi:10.1016/j.jchromb.2006.12.008

[14] Y. F. Sha, S. Shen and G. L. Duan, "Rapid Determination of Tramadol in Human Plasma by Headspace Solid-Phase Microextraction and Capillary Gas ChromatographyMass Spectrometry," Journal of Pharmaceutical and Biomedical Analysis, Vol. 37, No. 1, 2005, pp. 143-147. doi:10.1016/j.jpba.2004.09.050

[15] J. G. Li and H. X. Ju, "Simultaneous Determination of Ethamsylate, Tramadol and Lidocaine in Human Urine by Capillary Electrophoresis with Electrochemilumin escence Detection," Electrophoresis, Vol. 27, No. 17, 20 06, pp. 3467-3474. doi:10.1002/elps.200600135

[16] W. D. Cao, J. F. Liu, H. B. Qiu, X. R. Yang and E. K. Wang, "Simultaneous Determination of Tramadol and Lidocaine in Urine by End-Column Capillary Electrophoresis with Electrochemiluminescence Detection," Electroanalysis, Vol. 14, No. 22, 2002, pp. 1571-1576. doi:10.1002/1521-4109(200211)14:22<1571::AID-ELAN 1571>3.0.CO;2-X

[17] H. E. Abdellatef, M. M. El-Henawee, H. M. El-Sayed and M. M. Ayad, "Spectrophotometric and Spectrofluorimetric Methods for Analysis of Tramadol, Acebutolol and Dothiepin in Pharmaceutical Preparations," Spectrochimica Acta Part A: Molecular and Biomolecular Spectroscopy, Vol. 65, No. 5, 2006, pp. 1087-1092. doi:10.1016/j.saa.2006.02.008

[18] A. El-Gindy, A. Ashour, L. Abdel-Fattah and M. M. Shabana, "First Derivative Spectrophotometric, TLC-
Densitometric, and HPLC Determination of Acebutolol Hydrochloride in Presence of Its Acid-Induced Degradation Product," Journal of Pharmaceutical and Biomedical Analysis, Vol. 24, No. 4, 2001, pp. 527-534. doi:10.1016/S0731-7085(00)00451-9

[19] A. Küçük and Y. Kadıŏlu, "Determination of Tramadol Hydrochloride in Ampoule Dosage Forms by Using UV Spectrophotometric and HPLC-DAD Methods in Methanol and Water Media," Il Farmaco, Vol. 60, No. 2, 2005, pp. 163-169. doi:10.1016/j.farmac.2004.12.002

[20] E. M. P. J. Garrido, J. M. P. J. Garrido, F. Borges and C. Delerue-Matos, "Development of Electrochemical Methods for Determination of Tramadol/Analytical Application to Pharmaceutical Dosage Forms," Journal of Pharmaceutical and Biomedical Analysis, Vol. 32, No. 4-5, 2003, pp. 975-981. doi:10.1016/S0731-7085(03)00199-7

[21] J. X. Feng, X. Q. Wang, L. P. Wang and Y. C. Zhang, "Determination of Tramadol Hydrochloride with Two Point Potentiometric Titration," Chinese Journal of Analytical Chemistry, Vol. 29, No. 12, 2001, pp. 1487-1487.

[22] H. Y. Liu, J. J. Ren, Y. H. Hao and H. C. Ding, "Determination of Metoprolol Tartrate in Tablets and Human Urine Using Flow-Injection Chemiluminescence Method," Journal of Pharmaceutical and Biomedical Analysis, Vol. 42. No. 3, 2006, pp. 384-388. doi:10.1016/j.jpba.2006.04.008

[23] B. T. Zhang, L. X. Zhao and J. M. Lin, "Determination of Folic Acid by Chemiluminescence Based on Peroxomonosulfate-Cobalt(II) System," Talanta, Vol. 74, No. 5 , 2008, pp. 1154-1159. doi:10.1016/j.talanta.2007.08.027

[24] P. Fletcher, K. N. Andrew, A. C. Calokerinos, S. Forbes and P. J. Worsfold, "Analytical Applications of Flow Injection with Chemiluminescence Detection-A Review," Luminescence, Vol. 16, No. 1, 2001, pp. 1-23. doi:10.1002/bio.607

[25] K. R. Mervartova, M. Polasek and J. M. Calatayud, "Review: Recent Applications of Flow-Injection and Sequential-Injection Analysis Techniques to Chemiluminescence Determination of Pharmaceuticals," Journal of Pharmaceutical and Biomedical Analysis, Vol. 45, No. 3, 2007, pp. 367-381. doi:10.1016/j.jpba.2007.08.018

[26] J. Stauff and W. A. Jaechke, "A Chemiluminescence Tech- nique for Measuring Atmospheric Trace Concentrations of Sulphur Dioxide," Atmospheric Environment (1967), Vol. 9, No. 11, 1975, pp. 1038-1039. doi:10.1016/0004-6981(75)90028-1

[27] F. Meixner and W. Jaeschke, "Chemiluminescenzverfahren Zum Nachweis von Schwefeldioxid im Ppt-Bereich," Fresenius' Journal of Analytical Chemistry, Vol. 317, No. 3-4, 1984, pp. 343-344. doi:10.1007/BF00494487

[28] B. J. Hindson and N. W. Barnett, "Review: Analytical Applications of Acidic Potassium Permanganate as a Chemiluminescence Reagent," Analytica Chimica Acta, Vol. 445, No. 1, 2001, pp. 1-19. doi:10.1016/S0003-2670(01)01240-5

[29] M. Kato, M. Yamada and S. Suzuki, "Flavin Mononucleotide Sensitized and Polyoxyethylene (20) Sorbitan 
Tri- oleate Micelle-Enhanced Gas/Solution Chemiluminescence for Direct Continuous Monitoring of Sulfur Dioxide in the Atmosphere," Analytical Chemistry, Vol. 56, No. 13, 1984, pp. 2529-2534. doi: $10.1021 / \mathrm{ac} 00277 \mathrm{a} 059$

[30] Y. H. Li and J. R. Lu, "Flow Injection Chemiluminescence Determination of Naproxen Based on $\mathrm{KMnO}_{4}-\mathrm{Na}_{2}$ $\mathrm{SO}_{3}$ Reaction in Neutral Aqueous Medium," Analytica Chimica Acta, Vol. 577, No. 1, 2006, pp. 107-110. doi:10.1016/j.aca.2006.06.022

[31] S. A. Al-Tamrah, A. Townshend and A. R. Wheatley, "Flow-Injection Chemiluminescence Determination of Sulphite," Analyst, Vol. 112, No. 6, 1987, pp. 883-886. doi:10.1039/an9871200883
[32] Y. H. Li and J. R. Lu, "Direct Chemiluminescence Determination of Ibuprofen by the Enhancement of the KMnO4-Sulphite Reaction," Luminescence, Vol. 22, No. 4, 2007, pp. 326-330. doi:10.1002/bio.966

[33] M. C. S. Alonso, L. L. Zamora and J. M. Calatayud, "Flow-Injection with Chemiluminescence Detection for the Determination of Iproniazid," Analytica Chimica Acta, Vol. 437, No. 2, 2001, pp. 225-231. doi:10.1016/S0003-2670(01)00969-2

[34] Y. F. Zhuang and H. L. Song, "Sensitive Determination of Ketoprofen Using Flow Injection with Chemiluminescence Detection," Journal of Pharmaceutical and Biomedical Analysis, Vol. 44, No. 3, 2007, pp. 824-828. doi:10.1016/j.jpba.2007.03.014 